\title{
Erratum to: Comparison of mass spectrometric methods (TE, MTE and conventional) for uranium isotope ratio measurements
}

\author{
K. J. Mathew ${ }^{1,2}$ A. Hasozbek ${ }^{1,3}$
}

Published online: 30 October 2015

(C) Akadémiai Kiadó, Budapest, Hungary 2015

\section{Erratum to: J Radioanal Nucl Chem DOI 10.1007/s10967-015-4484-8}

Unfortunately, in the original publication of this paper, the second author's name is misspelt. The correct name is given in this erratum.

The online version of the original article can be found under doi:10.1007/s10967-015-4484-8.

K. J. Mathew

kattathu.mathew@srs.gov

1 New Brunswick Laboratory (NBL), U.S. Department of Energy, 9800 S Cass Ave, Argonne, IL 60439, USA

2 F/H Area Analytical Laboratories, Savannah River National Laboratory, Building 707-F, Aiken, SC 29808, USA

3 Dokuz Eylul University, Izmir, Turkey 